\title{
Silver coordination compounds as light-stable, nano-structured and anti-bacterial coatings for dental implant and restorative materials
}

\author{
Tünde Vig Slenters, ${ }^{a}$ Irmgard Hauser-Gerspach, ${ }^{b}$ Alma U. Daniels ${ }^{c}$ and Katharina M. Fromm*d
}

Silver coordination polymer chains were deposited on $\mathrm{Au}(111)$ as a model surface, as well as on gold alloy and titanium as dental implant and restorative materials. The topography of the surface was analysed on the model substrate and it was found to be a nano-structured crystalline material. In vitro investigations in a flow chamber imitating the oral environment prove the anti-bacterial properties of the silver compound.

\section{Introduction}

Over the past years, silver compounds ${ }^{1}$ and nanoparticles ${ }^{2}$ have been studied for their anti-microbial activity as replacements for antibiotics, against which bacteria become more and more resistant. In this context, and working on silver coordination compounds, ${ }^{3}$ we became particularly interested in applications for implantable materials, e.g. artificial prostheses, and understanding the activity of silver compounds with respect to chemical composition, nano-structuring and anti-microbial activity. While orthopedic operations are generally carried out under sterile conditions, biofilm formation and subsequent inflammatory host responses may occur later, e.g. as result of bacterial multiplication (septic failure, hematogenous seeding) ${ }^{4}$ Adhesion of bacteria to dental implant components and restorative materials is a prerequisite for the formation of a biofilm that may lead to the development of dental diseases like dental caries, periodontal diseases and peri-implantitis. ${ }^{5,6}$ To prevent bacterial adhesion to surfaces, the so far tested silver compounds turned out to be either too soluble, or, as far as nanoparticles are concerned, toxic and both are thus not usable for long term purposes. $^{7}$ As an alternative class of silver compounds, we propose coordination polymer networks to be tested as anti-bacterial coatings on implant components. As a special challenge, we chose to work with tooth implant materials, for which the additional condition of light stability is highly required. ${ }^{8}$ We report here on a) the nano-structured surface topology, b) the chemical composition and c) the antimicrobial properties obtained for the deposition of a silver coordination polymer compound onto implant titanium, dental gold alloy, and $\mathrm{Au}(111)$ as model surface.

${ }^{a}$ University of Basel, Dept of Chemsitry, Spitalstrasse 51, 4056 Basel, Switzerland

${ }^{b}$ Laboratory of Preventive Dentistry and Oral Microbiology, University of Basel, Basel, Switzerland

${ }^{c}$ Laboratory of Orthopaedic Biomechanics, University of Basel, Basel, Switzerland

${ }^{d}$ Department of Chemistry, University of Fribourg, Chemin du Musée 9, CH-1700 Fribourg, Switzerland. E-mail: katharina.fromm@unifr.ch; Tel: $+41263008732$

\section{Results and discussion}

\section{Coating}

As shown earlier, we are able to control the synthesis of different silver coordination polymer compounds based on $\mathrm{L}=$ ethanediyl bis(isonicotinate), such as the two polymorphs of $\left[\mathrm{Ag}(\mathrm{L}) \mathrm{NO}_{3}\right]_{n}$, 1a and 1b, $\left[\mathrm{Ag}(\mathrm{L})\left(\mathrm{NO}_{3}\right)\left(\mathrm{H}_{2} \mathrm{O}\right)\right]_{n}, \mathbf{2}$, and $\left[\mathrm{Ag}(\mathrm{L})\left(\mathrm{NO}_{3}\right)\left(\mathrm{H}_{2} \mathrm{O}\right)_{2}\right]_{n}, \mathbf{3}$ (Fig. 1). Compound 1 presents simple chains bridged into sheets via weak coordination of the nitrate anions, and the ligand in anti conformation, while $\mathbf{2}$ and $\mathbf{3}$ form double-chains with short $\mathrm{Ag}-\mathrm{Ag}$ contacts and gauche (2) or anti (3) conformations of L. ${ }^{9}$

In order to choose the appropriate compound for antimicrobial tests, two properties were required: i) light stability, and ii) (in)solubility of our compounds in biological media. For the first purpose, solutions of 1-3 in organic solvents were deposited on filter papers, and subsequently exposed to light (Philips $15 \mathrm{~W}$, from $10 \mathrm{~cm}$ distance) for $3.5 \mathrm{~h}$, and compared to

a)

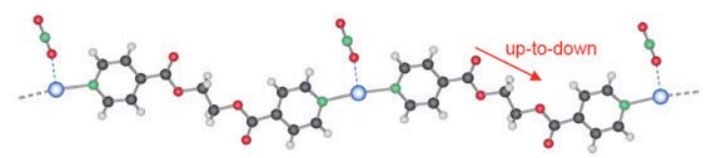

b)

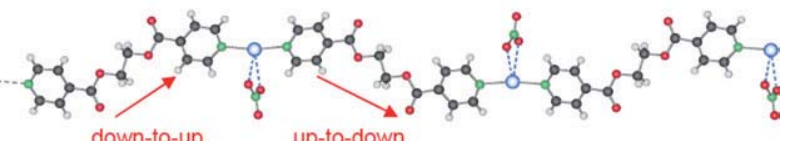

d)

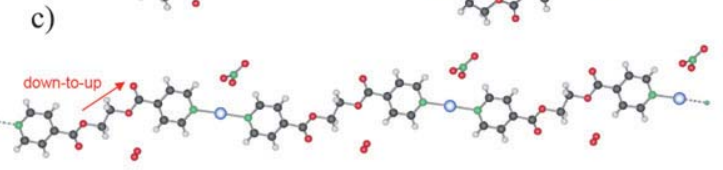

Fig. 1 Structures of $\left[\mathrm{Ag}(\mathrm{L}) \mathrm{NO}_{3}\right]_{n}$, 1a (a) and 1b (b), $\left[\mathrm{Ag}(\mathrm{L})\left(\mathrm{NO}_{3}\right)\right.$ $\left.\left(\mathrm{H}_{2} \mathrm{O}\right)\right]_{n}, 2(\mathrm{c})$, and $\left[\mathrm{Ag}(\mathrm{L})\left(\mathrm{NO}_{3}\right)\left(\mathrm{H}_{2} \mathrm{O}\right)_{2}\right]_{n}, 3$ (d); Color code: Ag: blue; O: red; N: green; C: grey; H: white. 
simple $\mathrm{AgNO}_{3}$ solutions at different concentrations. The results showed that the compound with the shortest and longest Ag contacts, 1a, showed the best light stability and also did not degrade when exposed to light for longer time scales (months). Thus, compound 1a was chosen for further tests on dental implant components, and its solubility was determined. A crop of $43 \mathrm{mg}$ of solid 1a was exposed to $1 \mathrm{ml}$ of phosphate buffer solution (PBS) (0.1 M pH 7.4) in a microcalorimeter in order to determine its solubility. No detectable heat of dissolution could be observed over a period of $168 \mathrm{~h}$, so the solubility product of $\mathbf{1 a}$ must be very low. The buffer solution was then subjected to atomic absorption spectrometry to determine the content of silver ions in solution to $2-5 \mathrm{ppb}$.

As substrates for the deposition of compound 1a, typical metallic dental implant and restorative materials were chosen: titanium (99.9\% Tritan, RematitanM, Dentaurum, Ispringen, Germany) (A), and a gold alloy (Au 71\%, Pt 3.7\%, Ag 12.7\%, $\mathrm{Cu} 10.8 \%$, Zn 1.1\%, Ir 0.1\%; Neocast 3, Cendres + Metaux SA, Biel-Bienne, Switzerland) (B). ${ }^{10}$ Both were used as polished (roughness $R_{\mathrm{a}}=0.24 \mu \mathrm{m}$ ) flat plates of $14 \times 14 \mathrm{~mm}$, the polishing being similar to that used for real dental applications. As a model surface, an oriented gold monolayer $\mathrm{Au}(111)$ on glass (C) was treated in the same way as the two implant material samples. Before deposition, the samples were cleaned with $\mathrm{H}_{2} \mathrm{SO}_{4}-\mathrm{H}_{2} \mathrm{O}_{2}$ $(30 \%)$, followed by thorough rinsing with ethanol and distilled water. Several different deposition techniques were used: i) immersion into the mother liquor (EtOH-THF) of a $2 \mathrm{mM}$ solution of 1a for continuous ongrowth for $\mathrm{A}, \mathrm{B}$ and $\mathrm{C}$, ii) dip-coating alternating a solution of $\mathrm{L}$ and $\mathrm{AgNO}_{3}$ (each $2 \mathrm{mM}$ ) for $\mathrm{B}$ and $\mathrm{C}$, iii) derivatives of $\mathrm{L}$ for grafting to the metal surface (isonicotinic acid for A, a disulfide derivative of our ligand for B and C). The first two methods yielded similar results in XPS, AFM and STM analyses, and will be discussed further. The third method, using an anchor molecule derived from ligand L, leads to the formation of less well ordered deposits in the form of larger crystallites. The latter are easily washed off the surface and were thus not suitable for application.

To identify the coatings obtained with the two first methods, XPS and powder X-ray measurements were used directly on the coated surfaces, and powder X-ray measurements were also performed on material which was cocrystallised from the same solutions as used for the surface coatings. All methods proved that i) a compound was deposited, and ii) that the deposited compound was (poly)crystalline 1a.

Additionally, AFM and SEM measurements were carried out on a coated surface of $\mathrm{Au}(111)$, allowing the investigation of the topology. As the implantable materials A and B were polished prior to deposition of 1a, the surface of these substrates was too rough for AFM, which was therefore carried out for sample $\mathrm{C}$ only. Tapping mode AFM was performed using a PycoLE System, Molecular Imaging, and silicon nitride cantilevers, $k=$ $42 \mathrm{~N} \mathrm{~m}^{-1}$, at force set point $3.8 \mathrm{~V}$ and scan rate 1 line $\mathrm{s}^{-1}$. Different positions of the sample were monitored. All experiments were performed at room temperature. The AFM revealed peak-like structures which were analyzed with respect to their height and width (Fig. 2). The surface pattern corresponds to Ostwald ripening motifs on a two-dimensional surface with a main interpeak distance of $20-30 \mathrm{~nm}$, a distance which is known to be ideal for cell ongrowth. ${ }^{11}$ From the mean peak height of 11-14 nm, the average polymer chain length, supposed to be standing upright on the surface, could be determined as an octameric chain $\left[\mathrm{Ag}_{8} \mathrm{~L}_{7}\right]$. From the width of the peaks, it can be concluded that more than one chain is attached to the surface to form such a peak. With approximations of the peak width of $c a$. 10-20 nm, and the unit cell of 1a, one can conclude that there are ca. 200-400 chains linked together within one peak. From the profile sequence in Fig. 2, it can be seen that the whole surface, also in between the peaks, is covered with product, even at lower thickness. SEM pictures of several samples ( $\mathrm{Au}(111)$ and coating types i) and ii)) confirm this analysis as shown in Fig. 3. The Ostwald ripening features on the surface are also clearly seen with this method. They also reveal the size distribution of the

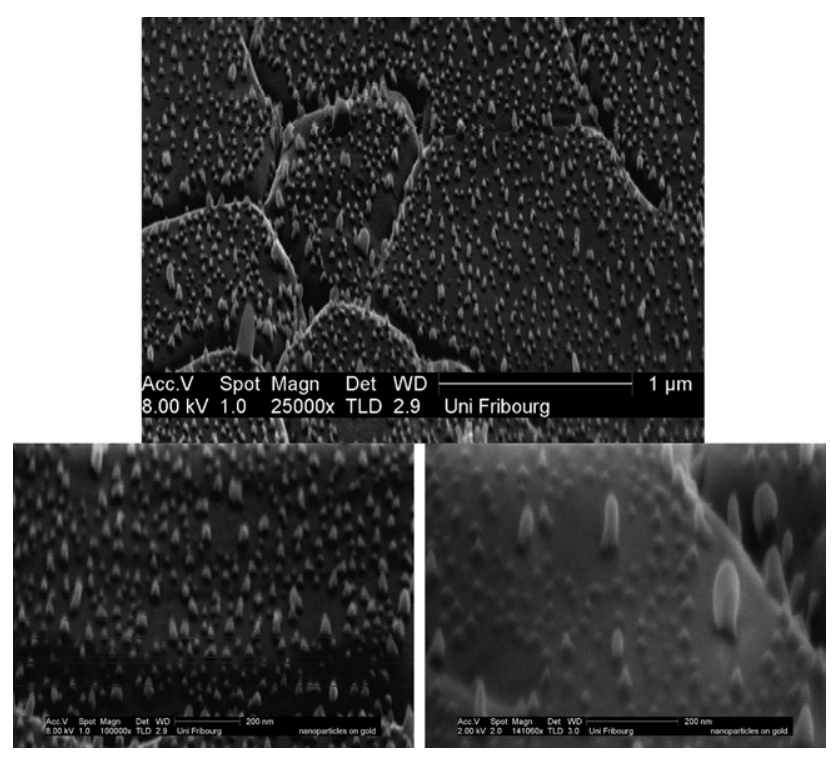

Fig. 3 SEM pictures of the deposit of $\mathbf{1 a}$ on $\mathrm{Au}(111)$.

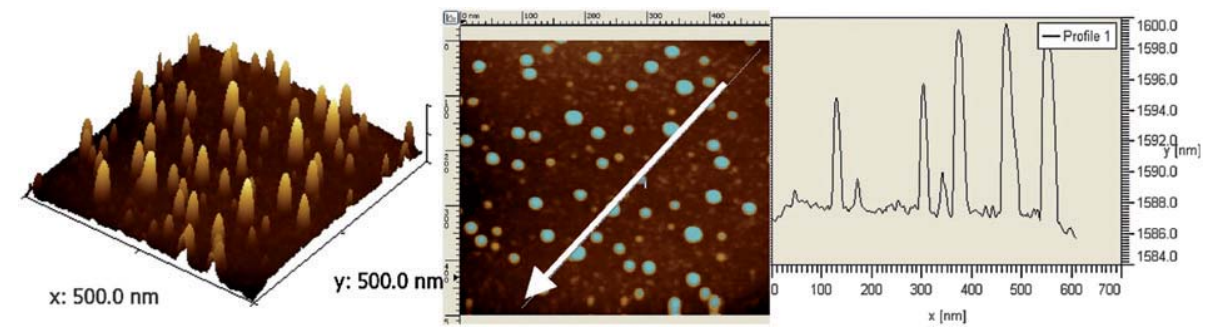

Fig. 2 AFM pictures (left, middle) and profile of the deposit of 1a on Au(111) along the white arrow (right). 
peaks on the surface. Several pictures were taken at different scales, and the peaks measured. Most, about $80 \%$, of the peaks seen by SEM are $c a .10-20 \mathrm{~nm}$ in height and have a mean diameter of 10-20 nm. The unit cell volume of 1a being $\mathrm{ca}$. $777 \AA^{3}$, this leads to roughly 25000 units of $1 \mathbf{a}$ within one such peak. About $10 \%$ of the surface peaks are $50-80 \mathrm{~nm}$ in height and have a mean diameter of $20 \mathrm{~nm}$ (roughly 60000 repeat units of 1a), whereas another $10 \%$ of the peaks are $>100 \mathrm{~nm}$ in height and have a mean diameter of $c a .50 \mathrm{~nm}(c a .500000$ repeat units of 1a). The coating can thus be estimated to be roughly $0.0125 \mathrm{~g} \mathrm{~m}^{-2}$ or $3 \times 10^{-11} \mathrm{~mol} \mathrm{~cm}^{-2}$. The surface coating was thus impossible to detect with an analytical balance.

From these data, it can be concluded that a well-defined, nanostructured topology is formed on the substrate surface, and that with high probability, similar structural features are obtained on the polished substrates of the titanium A and gold alloy B.

\section{Anti-bacterial testing}

The so prepared samples A and B were then transferred into a flow chamber (Scheme 1) for anti-microbial testing on dental materials. ${ }^{12}$

In a reservoir, a single bacterial strain, Streptococcus sanguinis DSM 20068 (German Collection of Microorganisms and Tissue Culture Cells, Braunschweig, Germany), suspended in sterilized human saliva, was added. S. sanguinis was selected as one of the known early dental colonizers. ${ }^{13}$ The saliva was collected and processed as described in a previous study. ${ }^{14}$ The treated samples, together with non-treated blanks, were exposed during $60 \mathrm{~min}$ at room temperature to a flow rate of the bacteria saliva suspension of $0.8 \mathrm{ml} \mathrm{min}{ }^{-1}$, which corresponds roughly to physiological oral conditions of low shear. ${ }^{15}$ The system was placed on a shaker adjusted to 260 impulses $\mathrm{min}^{-1}$ in order to maintain the homogeneity of the bacterial suspension. ${ }^{14}$ Thereafter, the test specimens were removed and analyzed microscopically. The vitality of adhered bacteria was evaluated by applying a dual fluorescent staining (Live/Dead BacLight Bacterial Viability Kit; MoBiTec, Luzern, Switzerland) according to Decker et al. ${ }^{16}$ which allows differentiation between vital and dead bacterial cells (Fig. 4).

The test specimens were removed from the flow chamber, carefully dipped into distilled water in order to eliminate planktonic and loosely attached cells, and covered with $7.5 \mu \mathrm{l}$ of staining solution for $15 \mathrm{~min}$ at room temperature in the dark. The

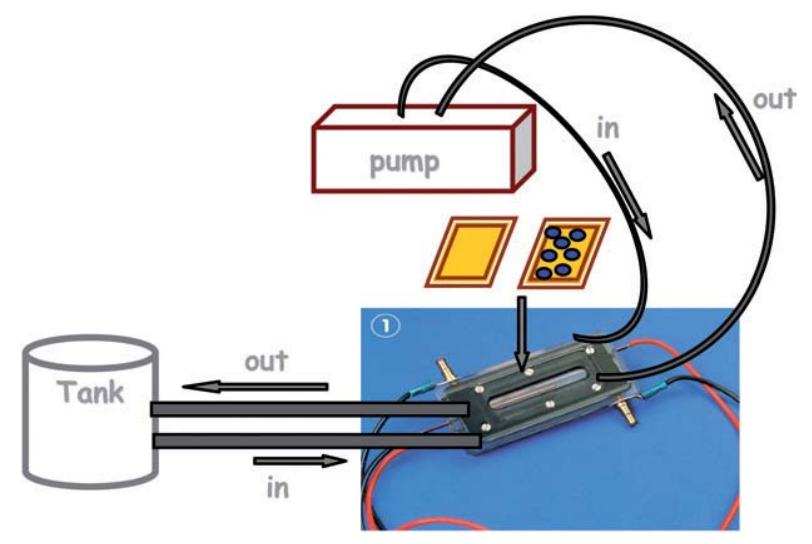

Scheme 1 Flow chamber for anti-bacterial test with S. sanguinis.
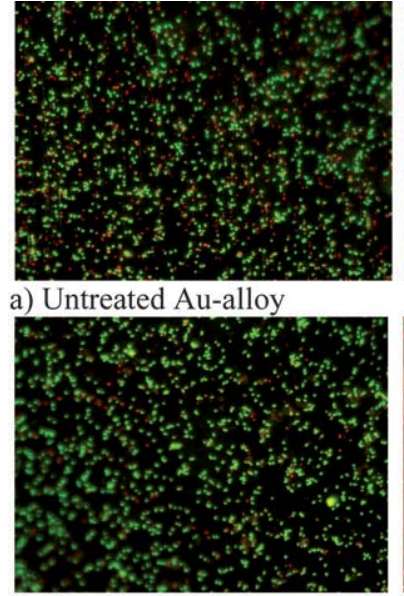

c) Untreated $\mathrm{Ti}$

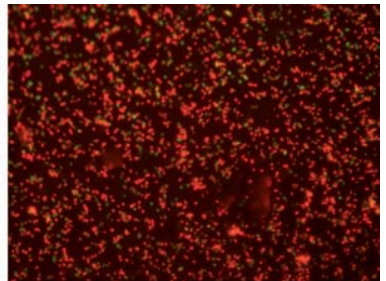

b) Treated Au-alloy

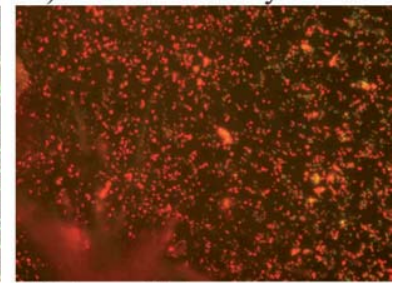

d) Treated $\mathrm{Ti}$

Fig. 4 Representative sector of the dental materials. Many bacteria attached to the untreated materials were stained green because they were still alive. Most on the treated samples were stained red indicating that they were dead at the time of staining.

cells were analyzed by epifluorescence microscopy (PROVIS AX70, Olympus AG, Volketswil, Switzerland). A total of twelve digital images (ColorView, Olympus AG, Volketswil, Switzerland) using two filters [blue excitation at $450-490 \mathrm{~nm}$ (FITC) and green excitation at $546 \mathrm{~nm}$ (rhodamine)] were obtained for each sample and the percentage of dead adherent cells was calculated. Each material was tested in at least four independent experiments. From the analysis of dead and alive bacteria on the treated metal surfaces, it can be concluded that compound 1a has definitely an anti-bacterial effect on $S$. sanguinis cells under the given conditions, by a reduction of adherent live bacteria of more than $90 \%$ for gold alloy and for titanium as compared to the corresponding non-treated samples. Together with the light stability and the low solubility, these results are encouraging for further studies in the field of silver-containing, anti-microbial surface coatings. Such experiments, as well as investigations on the mechanism of the anti-bacterial activity, are currently being carried out in our group, and are concerned with different $\mathrm{Ag}$ coordination polymer structures, as well as different bacterial strains. Thus, $\mathbf{1 a}$ and $\mathbf{1 b}$ show promising in situ activity against S. epidermidis as well.

\section{Conclusions}

We have presented here an easily accessible coating method for dental implant and restorative materials with a silver coordination polymer compound, analysed the surface structure and were able to show effective antimicrobial properties against S. sanguinis.

\section{Acknowledgements}

T. V. S. and K. M. F. thank the Swiss National Science Foundation for funding via the NCCR Nano, Basel, and for an interdisciplinary project. The authors thank Olivier Casse for AFM measurements, Teresa de los Arcos for XPS measurements, Elisabeth Filipuzzi for technical support, and Jürg Meyer 
for helpful discussions and support, and the Velux Foundation for financial support.

\section{References}

1 S. Ahmad, A. A. Isab, S. Ali and A. R. Al-Arfaj, Polyhedron, 2006, 25, 1633; O. B. Shcherbakov, G. I. Korchak, O. V. Surmasheva, I. M. Skorokhod, G. I. Mikhienkova and A. K. Gorval, Farm. Zh. (Kiev), 2006, 49; N. C. Kasuga, R. Yamamoto, A. Hara, A. Amano and K. Nomiya, Inorg. Chim. Acta, 2006, 359, 4412; R. Rowan, T. Tallon, A. M. Sheahan, R. Curran, M. McCann, K. Kavanagh, M. Devereux and V. McKee, Polyhedron, 2006, 25, 1771.

2 A. Panacek, L. Kvitek, R. Prucek, M. Kolar, R. Vecerova, N. Pizurova, V. K. Sharma, T. Nevecna and R. Zboril, J. Phys. Chem. B, 2006, 110, 16248; V. Alt, T. Bechert, P. Steinrucke, M. Wagener, P. Seidel, E. Dingeldein, E. Domann and R. Schnettler, Biomaterials, 2004, 25, 4383; C.-N. Lok, C.-M. Ho, R. Chen, Q.-Y. He, W.-Y. Yu, H. Sun, P. K.-H. Tam, J.-F. Chiu and C.-M. Che, J. Biol. Inorg. Chem., 2007, 12, 527; A. R. Shahverdi, A. Fakhimi, H. R. Shahverdi and S. Minaian, Nanomedicine, 2007, 3, 168; S. Pal, Y. K. Tak and J. M. Song, Appl. Environ. Microbiol., 2007, 73, 1712.

3 A. Y. Robin, J. L. Sague Doimeadios, A. Neels, T. Vig Slenters and K. M. Fromm, Inorg. Chim. Acta, 2007, 360, 212; A. Y. Robin and K. M. Fromm, Coord. Chem. Rev., 2006, 250, 2127; A. Y. Robin, J. L. Sague and K. M. Fromm, CrystEngComm, 2006, 8, 403; J. L. Sague and K. M. Fromm, Cryst. Growth Des., 2006, 6, 1566.
4 E. M. Hetrick and M. H. Schoenfisch, Chem. Soc. Rev., 2006, 35, 780; D. Campoccia, L. Montanaro and C. R. Arciola, Biomaterials, 2006, 27, 2331; Y. H. An and J. R. Friedman, J. Biomed. Mater. Res., 1998, 43, 338; M. Katsikogianni and Y. F. Missirlis, Eur. Cells Mater., 2004, $8,37$.

5 W. F. Liljemark and C. Bloomquist, Crit. Rev. Oral Biol. Med., 1996, 7, 180 .

6 J. M. ten Cate, Odontology, 2006, 94, 1.

7 N. C. Kasuga, A. Sugie and K. Nomiya, Dalton Trans., 2004, 3732; A. Melaiye, R. S. Simons, A. Milsted, F. Pingitore, C. Wesdemiotis, C. A. Tessier and W. J. Youngs, J. Med. Chem., 2004, 47, 973; S. A. Iqbal, M. A. Khan and S. M. Khan, Oriental J. Chem., 1999, 15, 572; I. Tsyba, B. B.-K. Mui, R. Bau, R. Noguchi and K. Nomiya, Inorg. Chem., 2003, 42, 8028.

8 T. Dorn, K. M. Fromm and C. Janiak, Aust. J. Chem., 2006, 59, 22.

9 A. Y. Robin, M. Meuwly, K. M. Fromm, H. Goesmann and G. Bernardinelli, CrystEngComm, 2004, 6, 336.

10 Neocast 3, Cendres \& Métaux SA, Biel-Bienne, Switzerland.

$11 \mathrm{H}$. Hoffmann, personal communication.

12 I. Hauser-Gerspach, E. M. Kulik, R. Weiger, E. M. Decker, C. Von Ohle and J. Meyer, Dent. Mater. J., 2007, 26, 361.

13 B. Nyvad and M. Kilian, Scand. J. Dent. Res., 1987, 95, 369.

14 R. Weiger, E. M. Decker, G. Krastl and M. Brecx, Arch. Oral Biol., 1999, 44, 621.

15 C. Dawes, S. Watanabe, P. Biglow-Lecomte and G. H. Dibdin, J. Dent. Res., 1989, 68, 1479.

16 E. M. Decker, R. Weiger, C. von Ohle, I. Wiech and M. Brecx, Clin. Oral Invest., 2003, 7, 98-102; E. M. Decker, Lett. Appl. Microbiol, 2001, 33, 188. 